\title{
United States - Final Determination with Respect to Certain Softwood Lumber from Canada (AB-2003-6, WT/DS257/AB/R)
}

\author{
HENRIK HORN \\ Institute for International Economic Studies, Stockholm University \\ PETROS C. MAVROIDIS \\ Columbia Law School, New York and University of Neuchâtel, Switzerland
}

\section{Introduction}

This note addresses the Word Trade Organization (WTO) dispute United States - Final Countervailing Duty Determination With Respect To Certain Softwood Lumber From Canada (WT/DS257); denoted "Softwood Lumber IV" below. The issues discussed by the Panel and the Appellate Body $(\mathrm{AB})$ in this dispute are very closely related to those examined by the Panel in United States - Preliminary Countervailing Duty Determination With Respect To Certain Softwood Lumber From Canada (WT/DS236); to be referred to as "Softwood Lumber III." This dispute was not appealed, and the $\mathrm{AB}$ thus did not have the opportunity to provide its view on the issues raised in the dispute. The fundamental character of several of the issues at stake in both these disputes makes the AB's determination in Softwood Lumber IV particularly interesting.

The Panel in Softwood Lumber IV - "the Panel" if not stated otherwise - saw itself as facing seven claims by Canada:

(1) The United States Department of Commerce (USDOC) erred in determining that "stumpage" is a financial contribution in the form of the provision of a good by provincial governments. 
(2) The USDOC erred in finding that the Canadian provincial stumpage programs confer a benefit.

(3) Even if stumpage does provide subsidies, the USDOC erred in not conducting a pass-through analysis in determining subsidization of softwood lumber in the case of certain upstream transactions for inputs.

(4) The USDOC failed to determine that the programs are specific subsidies within the meaning of Art. 2 of the Agreement on Subsidies and Countervailing Measures (SCM).

(5) The USDOC inflated the subsidy amount by using an inaccurate factor to convert the US log measurements into cubic meters.

(6) The United States did not comply with its obligations under Art. 12 SCM in regard to two aspects of the investigation, which concerned the change in the choice of benchmark state from the preliminary to the final determination, and the use of information based on a letter of the Maine Forest Products Council.

(7) The Byrd Amendment payments distorted the assessed support for the investigation, in violation of Art. 11.4 SCM.

The Panel found the following:

(1) The USDOC's determination that provision of stumpage constitutes a financial contribution in the form of the provision of a good or service was not inconsistent with Art. 1.1(a)(1)(iii) SCM.

(2) The USDOC's determination of the existence and amount of benefit to the producers of the subject merchandise was inconsistent with Art. 14 and 14(d) SCM.

(3) The USDOC's failure to conduct a pass-through analysis in respect of upstream transactions for $\log$ and lumber inputs between unrelated entities was inconsistent with Art. 10 SCM and Art. VI:3 of GATT 1994.

(4) The USDOC's determination that the provincial stumpage programs are specific was not inconsistent with Art. 2.1(c) SCM.

The Panel refrained from adjudicating on claims (5) and (6) for reasons of judicial economy, and Canada essentially withdrew claim (7).

Both Canada and the United States appealed certain findings by the Panel, giving the $\mathrm{AB}$ the opportunity to address claims (1)-(3) above. 
In this note, we will examine the AB's determination in regard to issues (2) and (3), concentrating on what we see as new elements in relation to Softwood Lumber III; we discussed the latter dispute in Horn and Mavroidis (2005). We will, however, refrain from discussing issue (1) - whether stumpage programs provide goods in the sense of the SCM - even though it may have broken some new legal ground. We simply find the issues addressed in this context to be of such a legal/technical nature that they lack more general interest. Let us just note that for reasons explained in Horn and Mavroidis (2005), we find it clear that from the point of view of the object and purpose of the SCM (if not the text and context), the stumpage programs must be seen as "providing goods," and that they may thereby confer a benefit. We thus fully agree with the $A B$ determination in this regard:

... we uphold the Panel's finding, in paragraph 7.30 of the Panel Report, that USDOC's "[d]etermination that the Canadian provinces are providing a financial contribution in the form of the provision of a good by providing standing timber to timber harvesters through the stumpage programmes" is not inconsistent with Article 1.1(a)(1)(iii) of the SCM Agreement.

$(\S 76$, italics in original)

We will discuss the AB's findings in regard to the calculation of benefit in Section 2 of this note, and address the pass-through issue in Section 3. Section 4 states our conclusion.

\section{The AB's findings on alternative benchmarks}

In establishing the magnitude of the benefit allegedly provided by the stumpage programs, the United States employed prices on stumpage contracts in various US states. The United States justified the procedure by arguing that, although the use of Canadian private stumpage prices would have been the preferred option to calculate the amount of benefit, in this particular case it was not possible to use such prices as the benchmark, since they were distorted and suppressed by the very measure under investigation. According to the United States, the tradedistorting potential of the government's provision of a good can be identified only by reference to an independent market price, i.e. a price that is unaffected by the very trade distortion the test is designed to identify. 
The Panel explicitly accepted that the United States might have a point, as a matter of economic logic. It would therefore be desirable to use other private-sector prices than those prevailing in the allegedly subsidizing country, in certain special situations. But the $S C M$ does not allow for this possibility in situations other than those in which no market price exists in the investigated country. In cases where market prices exist, WTO Members have to rely on them, even if the market at hand is small. The Panel felt that, economically irrational as this outcome may be, it did not have the mandate to modify the unambiguous terms of the Agreement:

... we do not believe that it would be appropriate for this Panel to substitute its economic judgement for that of the drafters. The Appellate Body has repeatedly emphasized, and we cannot but agree, that under Article 31 of the Vienna Convention on the Law of Treaties the interpretation of a treaty must be based on the text, as a proper interpretation is first of all a textual interpretation. For all the reasons set forth above, we do not consider that Article 14(d) can, consistent with customary rules of interpretation of public international law, be understood in the manner urged by the United States. We consider that our task is to interpret the applicable provisions as they exist and apply the text of the Agreement to the facts before us, not to rule on the economic logic of the text as it stands.

(§ 7.59, footnote omitted)

\subsection{The US appeal}

The Panel's finding was appealed by the United States. In the AB's words, the US claim was the following:

The United States argues that the Panel's interpretation of Article 14(d) is "completely at odds" with the concept of "benefit", as used in Article 1.1 of the SCM Agreement and as interpreted by the Appellate Body. The United States refers to the Appellate Body's interpretation of the term "benefit" in Article 1.1(b) in Canada - Aircraft, where it said that a government financial contribution confers a benefit if the "financial contribution' makes the recipient 'better off' than it would otherwise have been, absent that contribution", and that the marketplace provides the appropriate basis for comparison. According to the United States, the Panel's interpretation would not permit an investigating authority to determine whether the recipient is better off than it would have been absent the financial contribution. In addition, the United States contends 
that the term "market conditions" in Article 14(d) "can only mean a market undistorted by the government's financial contribution." Therefore, the United States submits that USDOC could rightfully reject the prices of private transactions in Canada as a benchmark.

$(\S 80$, italics in the original)

Consequently, the United States requested the AB to reverse the Panel's findings in this respect. The $\mathrm{AB}$ understood its task in the following terms:

The initial issue before us is whether an investigating authority may use a benchmark, under Article 14(d) of the SCM Agreement, other than private prices in the country of provision for determining if goods have been provided by a government for less than adequate remuneration. If our answer were to be in the affirmative, two additional questions would arise: (i) what are the specific circumstances under Article 14(d) in which an investigating authority may use a benchmark other than private prices in the country of provision; and (ii) assuming such circumstances exist, what alternative benchmarks may an investigating authority use to determine whether goods were provided by a government for less than adequate remuneration.

(§ 82, footnote omitted)

\subsection{The AB's findings}

The $A B$ partitions the claim by the United States into several distinct issues.

\subsubsection{Can alternative benchmarks be used?}

The first question addressed is whether Art. 14(d) of the SCM permits investigating authorities to use a benchmark other than private prices in the country of provision. The $\mathrm{AB}$ here first examines the text, and finds that the Panel made an erroneous interpretation of the phrase "in relation to" in Art. 14(d) SCM:

... The Panel reasoned that the phrase "in relation to" in the context of Article 14(d) means "in comparison with".... As we see it, the phrase "in relation to" implies a comparative exercise, but its meaning is not limited to "in comparison with". The phrase "in relation to" has a meaning similar to the phrases "as regards" and "with respect to". These phrases do not denote the rigid comparison suggested by the Panel, but may imply a broader sense of "relation, connection, reference". Thus, the use of the phrase "in relation to" in Article 14(d) suggests that, contrary to 
the Panel's understanding, the drafters did not intend to exclude any possibility of using as a benchmark something other than private prices in the market of the country of provision.

$(\S \S 88-89)$

The AB then moves to the context of Art. 14(d) SCM:

The chapeau of Article 14 requires that "any" method used by investigating authorities to calculate the benefit to the recipient shall be provided for in a WTO Member's legislation or regulations, and it requires that its application be transparent and adequately explained. The reference to "any" method in the chapeau clearly implies that more than one method consistent with Article 14 is available to investigating authorities for purposes of calculating the benefit to the recipient. The Panel's interpretation of paragraph (d) that, whenever available, private prices have to be used exclusively as the benchmark, is not supported by the text of the chapeau ...

In addition, a wider interpretation of the concept "in relation to" is mandated also due to the object and purpose of Art. 14 SCM. The AB here relies on the argument that government subsidies may distort private-sector prices, if the private sector is sufficiently small relative to the government sector:

... the determination of the existence of a benefit is a necessary condition for the application of countervailing measures under the SCM. If the calculation of the benefit yields a result that is artificially low, or even zero, as could be the case under the Panel's approach, then a WTO Member could not fully offset, by applying countervailing duties, the effect of the subsidy as permitted by the Agreement.

On the basis of these findings, the AB concludes that the Panel's interpretation of Art. $14(\mathrm{~d})$ is overly restrictive. Other prices than those in the country of provision can be used as benchmarks even when the latter prices exist.

\subsubsection{When can alternative benchmarks be used?}

The second issue decided by the $\mathrm{AB}$ is: when may an investigating authority use a benchmark other than private prices in the country of provision? The United States argued in its appeal that this possibility is not restricted to situations where no privately determined domestic 
price exists at all, but also applies to situations where such prices exist, but are distorted by the subsidy. The $\mathrm{AB}$ here argues that:

... there may be little difference between situations where the government is the sole provider of certain goods and situations where the government has a predominant role in the market as a provider of those goods. Whenever the government is the predominant provider of certain goods, even if not the sole provider, it is likely that it can affect through its own pricing strategy the prices of private providers for those goods, inducing the latter to align their prices to the point where there may be little difference, if any, between the government price and the private prices. This would be so even if the government price does not represent adequate remuneration. The resulting comparison of prices carried out under the Panel's approach to interpreting Article 14(d) would indicate a "benefit" that is artificially low, or even zero, such that the full extent of the subsidy would not be captured, as the Panel itself acknowledged. As a result, the subsidy disciplines in the SCM Agreement and the right of Members to countervail subsidies could be undermined or circumvented when the government is a predominant provider of certain goods.

It appears to us that the language found in Article 14(d) ensures that the provision's purposes are not frustrated in such situations. Thus, while requiring investigating authorities to calculate benefit "in relation to" prevailing conditions in the market of the country of provision, Article 14(d) permits investigating authorities to use a benchmark other than private prices in that market. When private prices are distorted because the government's participation in the market as a provider of the same or similar goods is so predominant that private suppliers will align their prices with those of the government-provided goods, it will not be possible to calculate benefit having regard exclusively to such prices.

\section{But the $\mathrm{AB}$ also cautions that the possibility of using alternative benchmarks is very limited:}

... We agree with the United States that " $[t]$ he fact that the government is a significant supplier of goods does not, in itself, establish that all prices for the goods are distorted". Thus, an allegation that a government is a significant supplier would not, on its own, prove distortion and allow an investigating authority to choose a benchmark other than private prices in the country of provision. The determination of whether private prices are distorted because of the government's predominant role in the market, as a provider of certain goods, must be made on a case-by-case 
basis, according to the particular facts underlying each countervailing duty investigation.

On the basis of this reflected reasoning, the $\mathrm{AB}$ concludes that:

... an investigating authority may use a benchmark other than private prices of the goods in question in the country of provision, when it has been established that those private prices are distorted, because of the predominant role of the government in the market as a provider of the same or similar goods.

$\S(\S 103$, underlining added $)$

The $A B$ thus reverses the Panel's finding and determines that prices other than private-sector prices in the country of provision may be used:

... when it has been established that those private prices are distorted because of the predominant role of the government in the market as a provider of the same or similar products ...

\subsubsection{Which alternative benchmarks can be used?}

The $\mathrm{AB}$ reports that at the oral hearing, Canada suggested three possibilities:

... (i) a benchmark constructed using a methodology similar to that provided in Article 2.2 of the Agreement on Implementation of Article VI of the General Agreement on Tariffs and Trade 1994 (the "Anti-Dumping Agreement"); (ii) a proxy estimated on the basis of costs of production; and (iii) a methodology that examines whether government prices are consistent with market principles ...

The United States instead proposed world market prices available in the country of provision, or an examination of the consistency of the contested measures with market principles. The $A B$ agreed to these proposals in very general terms. But it refrained from taking any more definite stands, since the issue before it was limited to whether the method actually employed by the US authority was legal.

2.2.4 The legality of the method employed by the United States The Panel's finding that the method employed by the United States to use prices from neighboring US states as benchmarks - was illegal 
under Art. 14(d) SCM, was based on an interpretation of this Article that the $\mathrm{AB}$ had hitherto rejected. The $\mathrm{AB}$ therefore reversed the Panel's finding. Having reversed this finding, the $A B$ would have been required to determine the legality of the US method de novo. But it refrained from doing this, since, in its view, it lacked the necessary factual information that would have allowed it to complete such a legal analysis.

\subsection{Discussion}

As a matter of economic logic, we fully agree with the $A B$ that alternative benchmarks are necessary in cases where the government significantly influences private prices, directly or indirectly. As emphasized by the $A B$, when undertaking such calculations, it will be necessary to adjust the benchmark prices, in order to appropriately account for various differences between different markets, such as differences in production costs, transport costs, costs of capital, or differences in taxation that may directly or indirectly affect any price comparison, etc. But while as a matter of principle it is necessary to use alternative benchmarks, it will in practice most likely be very hard to determine these in a satisfactory fashion. As we discussed in Horn and Mavroidis (2005), there are fundamental difficulties with the SCM in this respect.

While we are sympathetic to the AB's findings from this perspective, although concerned about its practical aspects, we see a legal problem with the $A B$ 's textual analysis. The $A B$ seems to be drawing very farreaching conclusions from the distinction it draws between the Panel's interpretation of "in relation to" as meaning "in comparison with," and their own, wider interpretation of "relation, connection, reference." From this wider interpretation, the $A B$ infers that:

... the drafters did not intend to exclude any possibility of using as a benchmark something other than private prices in the market of provision.

We fail to see that such an interpretation of the drafters' intentions could be read from the three words "relation, connection, reference." If the drafters intended the term "in relation to" to be of such an indicative nature, why were they not more explicit on this score, by including a term such as "inter alia"? If silence means something (as the $\mathrm{AB}$ has time and again told us), then clearly in this case it must 
mean that the founding fathers had no wish to provide alternative benchmarks.

We are thus led to conclude that the Panel's interpretation is more correct than that of the $\mathrm{AB}$, from a textual point of view. This is what prompted us, in our report of last year, to recommend a formal amendment of the SCM in this respect. As we see it, the AB's finding is effectively impermissible judicial activism, since the $A B$ 's interpretation of Art. 14(d) SCM amounts to a formal amendment of the provision. As Art. X of the Agreement Establishing the WTO makes plain, this is the exclusive privilege of the Herren der Verträge, the WTO Membership. We believe that even an authentic interpretation (as per Art. IX of the Agreement Establishing the WTO) is legally impossible here, since, what is requested is not a specification of a term, but, instead, a complete turnaround of the situation (by providing for the possibility, nonexisting in the current text, to use alternative benchmarks every time a situation similar to that of the instant case is present).

\section{When is a pass-through analysis necessary?}

The third substantive issue that the $\mathrm{AB}$ addresses concerns the need for analysis of the pass-through of any subsidy to log production, to downstream lumber production. Canada claimed before the Panel that in instances where the recipient of the (alleged) subsidy is at arm's length from the subject of the countervailing duty - the lumber producer - the United States was required to conduct a pass-through analysis. The United States, on the other hand, claimed that there was no such necessity when the subsidy determination was made on an aggregate basis.

In the view of the Panel,

[t] he heart of the pass-through issue is whether, where a subsidy is received by someone other than the producer or exporter of the product under investigation, the subsidy nevertheless can be said to have conferred benefits in respect of that product...

(§ 7.91 Panel report)

The Panel concluded that this cannot be taken for granted. With regard to the US argument that the analysis was performed on an aggregate basis, the Panel responded:

Thus, contrary to the US argument, the question of pass-through has to do with correctly identifying the subsidy amount attributable to the 
subject merchandise entering the US (the numerator). The fact that the US conducted the lumber investigation on an aggregate basis does not prevent and cannot cure the overall numerator (the aggregate subsidy amount from the stumpage programmes) from being overstated where upstream transactions for inputs between unrelated entities are present and subsidies have not been passed through.

The Panel consequently found in favor of Canada.

\subsection{The US appeal}

The United States appealed the Panel's determination, claiming that no pass-through analysis of subsidization to log production for the production of softwood lumber was necessary in two specific situations involving arm's-length relationships:

(1) where a tenured timber harvester owns a sawmill and processes some of the logs it harvests into softwood lumber, but at the same time sells, at arm's length, some of the logs it harvests to unrelated sawmills for processing into lumber; and

(2) where a tenured timber harvester processes logs it harvests into lumber and sells, at arm's length, some or all of this lumber to lumber re-manufacturers for further processing.

\subsection{The AB's findings}

The $\mathrm{AB}$ first points out that, according to the text General Agreement on Tariffs and Trade (GATT) 1994 and the SCM, as well as according to case law,

... where countervailing duties are used to offset subsidies granted to producers of input products, while the duties are to be imposed on processed products, and where input producers and downstream processors operate at arm's length, the investigating authority must establish that the benefit conferred by a financial contribution directly on input producers is passed through, at least in part, to producers of the processed product subject to the investigation.

$(\S 146$, italics in original $)$

The $\mathrm{AB}$ also dismisses the argument by the United States that:

... no pass-through analysis was required with respect to arm's length sales of logs and lumber by tenured timber harvesters owning sawmills, 
to unrelated sawmills and re-manufacturers, because Article 19.3 recognizes that exporters who are not investigated individually may nevertheless be subject to countervailing duties; accordingly, it is not necessary, in an aggregate investigation, to determine whether individual producers or exporters actually received subsidies.

...[w]here the producer of the input is not the same entity as the producer of the processed product, it cannot be presumed, however, that the subsidy bestowed on the input passes through to the processed product. In such case, it is necessary to analyze to what extent subsidies on inputs may be included in the determination of the total amount of subsidies bestowed upon processed products. For it is only the subsidies determined to have been granted upon the processed products that may be offset by levying countervailing duties on those products.

The $\mathrm{AB}$ agrees with the United States that Members are allowed to perform an investigation on an aggregate basis. But it nevertheless rejects the US claim that a pass-through analysis is for this reason not required:

... country-wide or company-specific countervailing duty rates may be imposed under Part V of the SCM Agreement only after the investigating authority has determined the existence of subsidization, injury to the domestic industry, and a causal link between them ...

$(\S 154$, italics in original)

\subsubsection{Sales of logs at arm's length by timber harvesters/sawmills} to independent lumber producers

We now turn to the first of the two situations that the United States wanted the $\mathrm{AB}$ to examine: where logs are sold by vertically integrated harvesters/primary lumber producers to independent primary lumber producers. The United States claimed that in such a case there was no need for a pass-through analysis, because the harvester/sawmill was a producer of the product subject to the investigation by processing some logs into softwood lumber in its own sawmill.

The $\mathrm{AB}$ understands the United States to be arguing that the arm'slength sales may be cross-subsidizing the harvester/lumber producer's own primary lumber production:

... We understand the United States to argue that benefits, initially attached to logs, but retained by a harvester/sawmill when the logs are 
sold in arm's length transactions to unrelated buyers, may be used by such a vendor to "cross-subsidize" its own production of softwood lumber processed in-house from other logs ...

But the $\mathrm{AB}$ does not accept this argument as a reason for not performing a pass-through analysis:

... We agree, in the abstract, that a transfer of benefits from logs sold in arm's length transactions to lumber produced in-house from different logs is possible for a harvester that owns a sawmill. But whether, in fact, this occurs depends on the particular case under examination. In any event, these arm's length sales at issue concern logs, which are not products subject to the investigation. Accordingly, in cases where logs are sold by a harvester/sawmill in arm's length transactions to unrelated sawmills, it may not be assumed that benefits attaching to the $\operatorname{logs}$ (non-subject products) automatically pass through to the lumber (the subject product) produced by the harvester/sawmill. A passthrough analysis is thus required in such situations.

$(\S 157$, italics in original)

Indeed, we disagree with the proposition that, as long as an enterprise produces products subject to an investigation, any benefits accruing to the same enterprise from subsidies conferred on any different products it produces (which are not subject to that investigation), could be included, without need of a pass-through analysis, in the total amount of subsidization found to exist for the investigated product, and that may be offset by levying countervailing duties on that product. We conclude that the pass-through of the benefit cannot be presumed with respect to arm's length sales of logs by harvesters, who own sawmills, to unrelated sawmills, for further processing.

$(\S 158$, italics in original)

The AB thus upheld the Panel's finding that the lack of passthrough analysis violated US obligations under Arts. 10 and 32.1 SCM, and Art. VI:3 of the GATT 1994.

\subsubsection{Sales of lumber at arm's length by timber harvesters/sawmills to independent lumber re-manufacturers}

The final issue addressed by the $A B$ is the US claim that no pass-through analysis is needed in a case where a tenured timber harvester processes logs it harvests into lumber and sells, at arm's length, some or all of the 
lumber to re-manufacturers for further processing. The $A B$ starts by emphasizing that in such a case:

... the products of both the harvesters/sawmills and the re-manufacturers are subject to the investigation ...

$(\S 161$, italics in original)

The $\mathrm{AB}$ then quotes from the Panel report:

... some portion of any subsidy from stumpage is attributable to the harvester/sawmill's production of the lumber for re-manufacturing and some is attributable to the other products (including lumber) that the harvester/sawmill produces. Here, if the subsidies attributable to the lumber for re-manufacturing are not passed through to the re-manufacturer that purchases it, then those subsidies should not be included in the numerator of the subsidization equation, as in this situation it is the re-manufactured product, not the upstream lumber product, that is the subject merchandise under investigation.

The $\mathrm{AB}$ dismisses this reasoning as a confusing of pass-through questions that may arise when individual enterprises are investigated with questions arising when calculations are made on an aggregate basis:

... Once it has been established that benefits from subsidies received by producers of non-subject products (that is, inputs) have passed through to producers of subject products (primary and remanufactured softwood lumber), we do not see why a further pass-through analysis between producers of subject products should be required in an investigation conducted on an aggregate basis. In this situation, it is not necessary to calculate precisely how subsidy benefits are divided up between the producers of subject products in order to calculate, on an aggregate basis, the total amount of subsidy and the country-wide countervailing duty rate for those subject products.

$(\S 163$, italics in original)

The $A B$ notes that this procedure may result in the imposition of duties on shipments of re-manufactured softwood that is not being subsidized. But this is nevertheless "by the book":

.. Article 19 of the SCM Agreement contemplates the imposition of a country-wide countervailing duty rate, even when a specific exporter is not subsidized, or when that country-wide rate does not match the 
precise amount of subsidization benefiting a specific shipment ... [T] he possibility for an exporter not investigated individually to request, pursuant to Article 19.3, an expedited review to establish an individual countervailing duty rate for that exporter, also confirms that a countrywide duty rate may, in principle, be imposed. However, the pass-through question would not be the same when determining, through the review procedure provided for in Article 19.3, an individual countervailing duty rate for the exporter that requested the review. In such a review, it is likely that a pass-through analysis would be required to determine whether input subsidies on logs, having passed through to the production of softwood lumber inputs, have passed through also to remanufactured lumber produced from those inputs by the particular exporter.

( $(164$, italics in original, footnote omitted)

The $A B$ thus reversed the Panel's finding that the failure to conduct a pass-through analysis in respect of arm's-length sales of lumber by tenured harvesters/sawmills to unrelated re-manufacturers violates Arts. 10 and 32.1 SCM and Art. VI:3 GATT 1994.

\subsection{Discussion}

From an economic perspective, whether a pass-through analysis should be undertaken or not clearly depends on what the purpose of such an analysis would be, which in turn must reflect the purpose of the SCM and Art. VI GATT. But if the purpose is to prevent injury to import-competing industry, and the countervailing duty (CVD) should only just offset such injury, then it is always necessary to perform a pass-though analysis, regardless of the vertical structure of the industry in the allegedly subsidizing country. This is, of course, the purpose of CVDs. Contrary to what seems to be the prevailing view among the parties to this dispute, and also the adjudicating bodies, there is no guarantee that in the case of a vertically integrated structure, subsidies to upstream activities will affect downstream production (even though there is probably a presumption to this effect). And in the case of arm's-length relationships, it is entirely possible, if not likely, that there will be effects on downstream production from upstream subsidization.

The $A B$ seems to agree with this view, since, if it thought that a pass-through analysis was unnecessary, presumably it would have said so, and suggested what should take place instead. But it did not. The reason it reversed the Panel's findings with respect to sales of lumber at arm's length by timber harvesters/sawmills to independent 
lumber re-manufactures is that in such cases, because duties can be imposed on an aggregate basis, there is a legislative presumption that exported softwood lumber from noninvestigated Canadian producers has been subsidized (Art. 19.3 SCM), and therefore there is no need for an additional investigation to the same effect. One may indeed question the reasonableness of this provision. But such a task was not before the $\mathrm{AB}$, and for this reason we leave this issue aside. What can be noted, however, is that an aggregate procedure must by necessity be imprecise, and lead to duties on individual products that do not reflect the actual extent of subsidization. But it is hard to say anything about how such a calculation should be performed from an economic point of view. Also, economic operators who have not been subsidized can always request refund of duties, assuming they have proven that they never benefited from a subsidy. There is, by virtue of Art. 19.3 SCM, a reversal of the burden of proof, in the sense that, CVDs can be imposed without a prior demonstration of subsidization.

\section{Concluding remarks}

The Panel and the $A B$ seem in this dispute to have moved in the direction of generally both desiring and requiring a pass-through analysis, in contrast to the Panel's position in Softwood Lumber III. As we have explained, we find such a move intellectually appealing. We also find the AB's approach refreshing in being less narrowly textual, and placing greater emphasis on context and purpose, even though, regrettably, this time the $\mathrm{AB}$ went too far in this direction. We find it hard to interpret Art. 14(d) SCM, as it now stands, so as to allow for alternative benchmarks of the type proposed by the United States to be used. While the Panel acknowledged this restriction imposed by the Agreement, the $\mathrm{AB}$ neglected it, and by taking on the role of the legislator, the $\mathrm{AB}$ thus contravened Art. 3.2 DSU.

\section{References}

Horn, H. and Mavroidis, P. C. (2005). United States - Preliminary Determination with Respect to Certain Softwood Lumber from Canada: What is a subsidy? In H. Horn and P. C. Mavroidis, eds., Principles of World Trade Law: The World Trade Organization. The Case Law of 2002. The American Law Institute and Cambridge University Press, Cambridge, UK. 